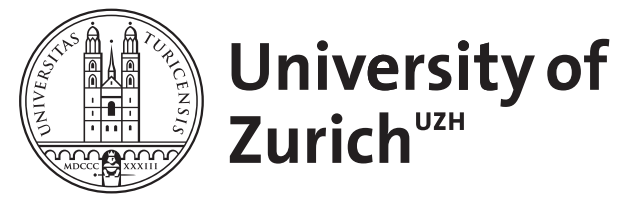

Zurich Open Repository and Archive

University of Zurich

University Library

Strickhofstrasse 39

CH-8057 Zurich

www.zora.uzh.ch

Year: 2011

MR coronary angiography, back to the future?

Gerber, B L

DOI: https://doi.org/10.1159/000327561

Posted at the Zurich Open Repository and Archive, University of Zurich

ZORA URL: https://doi.org/10.5167/uzh-51588

Journal Article

Published Version

Originally published at:

Gerber, B L (2011). MR coronary angiography, back to the future? Cardiology, 118(2):121-123.

DOI: https://doi.org/10.1159/000327561 


\title{
MR Coronary Angiography, Back to the Future?
}

\author{
Bernhard L. Gerber \\ Cliniques Universitaires St. Luc, Université Catholique de Louvain, Brussels, Belgium
}

Invasive $\mathrm{X}$-ray coronary angiography $(\mathrm{XCA})$ remains the clinical reference method for the detection of coronary artery disease in patients. Each year, several millions of XCAs are performed worldwide to make the diagnosis of coronary artery disease and to select therapeutic strategies. Although XCA is definitely a very effective diagnostic tool, it is undoubtedly an invasive procedure with a nonnegligible risk of morbidity and mortality. Because of this, it usually needs to be performed in a hospital setting, and is therefore associated with high costs [1-3]. Furthermore, in overall clinical practice, XCA is clearly overused and has a low diagnostic yield. Indeed a recent study [4] reported that only one third of patients without known coronary artery disease who underwent elective XCA have obstructive coronary artery disease, leading to revascularization procedures. Therefore better strategies are required to limit the intense clinical use and the high amounts of nondiagnostic XCAs. Ideally, XCA would only be needed in patients who have significant coronary artery disease, and who will undergo revascularization therapy.

The ability to detect or exclude coronary artery disease by noninvasive imaging techniques could be an attractive approach to select patients prior to XCA. Yet such noninvasive detection of coronary artery disease is technically challenging. Indeed, the coronary arteries are of a small size and have a complex 3-dimensional (3D) trajectory around the heart. Furthermore, they present a complex motion resulting both from cardiac contraction and respiration. Currently, there are two techniques which compete for such noninvasive coronary imaging: MR and CT.

Noninvasive coronary artery imaging by MR (MRCA) was introduced almost 20 years ago [5] and has steadily evolved over time. The first MRCA acquisitions were performed during breathholds. This, however, limited acquisition to single $2 \mathrm{D}$ slices allowing only visualization of short segments of proximal coronary arteries. The introduction of free-breathing navigator sequences $[6,7]$ by the end of the 1990s made it possible to perform longer $3 \mathrm{D}$ acquisitions with higher spatial resolution, and offered the possibility to visualize longer segments of the coronary arteries with higher spatial resolution. Initial approaches required individual prescription of multiple coronary artery segments on localizer images, a very time-consuming approach resulting in study durations of about $1 \mathrm{~h}$ to visualize all coronary artery segments. In 2005, a faster approach was proposed, i.e. whole-heart MRCA imaging [8-10]. With this approach, instead of localizing individual coronary arteries at the time of acquisition, only one large axial 3D volume encompassing the entire heart with all coronary arteries is acquired. Similar to CT, the individual coronaries are

\section{KARGER}

Fax +4161306 1234

E-Mail karger@karger.ch

www.karger.com
(C) 2011 S. Karger AG, Basel

$0008-6312 / 11 / 1182-0121 \$ 38.00 / 0$

Accessible online at:

www.karger.com/crd
Bernhard L. Gerber, MD, PhD, FESC, FACC

Cliniques Universitaires St. Luc

Université Catholique de Louvain

Avenue Hippocrate 10, BE-1200 Brussels (Belgium)

E-Mail Bernhard.Gerber@ clin.ucl.ac.be 
visualized using off-line postprocessing and reconstruction of curvilinear multiplanar projections of the 3D stack. Whole-heart MRCA allowed significant shortening of acquisition times to less than $30 \mathrm{~min}$. Poor navigator efficiency when patients have irregular breathing patterns or when their diaphragmatic position changes during the acquisition (navigator drift) remained, however, a major limitation of free-breathing navigator imaging. Because in this case a lot of data falling outside of the navigator window are rejected, acquisition may last much longer than expected or even fail completely. To overcome this limitation, it was recently proposed to limit respiratory motion by abdominal banding. Also, the most recent MRCA techniques make use of multichannel coils to allow parallel imaging with higher acceleration factors to further shorten acquisition time and of higher field strength (3-tesla) imaging and infusion of contrast agents to increase signal-to-noise ratio [11].

Multidetector computed tomography (MDCT) is a serious contender of MRCA for noninvasive coronary imaging. Although the technique was introduced later than MRCA, its abilities to noninvasively image the coronary system have developed far more rapidly than those of MRCA. The most important advantage of MDCT over MRCA is faster acquisition time. Indeed with the most recent 256- to 320-slice MDCT systems, acquisitions can be performed within only one or two heartbeats. MDCT also has a higher signal-to-noise ratio, and about $9 \times$ higher spatial resolution allowing better image quality than MRCA. Because of these advantages, in direct head to head comparison $[12,13]$, MDCT was found to have higher diagnostic accuracy than recent MRCA tech- niques. The most important disadvantage of MDCT as opposed to MRCA remains, however, the exposure to ionizing radiation, with the potential risk of radiationinduced cancer [14].

Chen et al. [15], in a recent issue of Cardiology, performed a very interesting study evaluating the diagnostic accuracy of the most recent state of the art MRCA technique: i.e. 3-tesla whole-heart MRCA imaging with 32-channel coil parallel imaging, infusion of contrast agent, and abdominal banding. They report impressive results: indeed the authors were able to perform such MRCA with very short acquisition time. On average, acquisitions lasted only $9 \mathrm{~min}$. The authors also had a very high success rate of $95 \%$, and reported that most studies had very good image quality, allowing interpretation of over $90 \%$ of all coronary segments. Hence, the diagnostic accuracy of MRCA versus XCA was found to be very good: indeed on a per-segment and per-patient basis, sensitivity to indentify significant coronary artery disease was 92 and 95\%, respectively. Specificity to exclude disease was also high: $86 \%$ on a per-segment basis and $87 \%$ on a per-patient basis. These exciting results are comparable to those reported with the latest generation of MDCT scanners [16]. Of course such impressive singlecenter data call for a confirmation in a multicenter setting with centralized reading, as well as for direct head to head comparison with the latest generation of MDCT systems. Overall this promising work suggests that MRCA is far from being an obsolete technique of the past. On the contrary, it suggests that MRCA still has a bright future with the ability to compete favorably against MDCT, yet without its inherent limitations.

\section{References}

1 Scanlon PJ, Faxon DP, Audet AM, Carabello B, Dehmer GJ, Eagle KA, Legako RD, Leon DF, Murray JA, Nissen SE, et al: ACC/AHA guidelines for coronary angiography. A report of the American College of Cardiology/ American Heart Association Task Force on practice guidelines (Committee on Coronary Angiography). Developed in collaboration with the Society for Cardiac Angiography and Interventions. J Am Coll Cardiol 1999;33:1756-1824.

2 Johnson LW, Krone R: Cardiac catheterization 1991: a report of the Registry of the Society for Cardiac Angiography and Interventions (SCA\&I). Cathet Cardiovasc Diagn 1993;28:219-220.
3 Wyman RM, Safian RD, Portway V, Skillman JJ, McKay RG, Baim DS: Current complications of diagnostic and therapeutic cardiac catheterization. J Am Coll Cardiol 1988; 12:1400-1406

4 Patel MR, Peterson ED, Dai D, Brennan JM, Redberg RF, Anderson HV, Brindis RG, Douglas PS: Low diagnostic yield of elective coronary angiography. N Engl J Med 2010; 362:886-895.

5 Edelman RR, Manning WJ: Magnetic resonance angiography and flow quantification of coronary arteries. Magn Reson Imaging Clin N Am 1993;1:339-347.
6 Botnar RM, Stuber M, Kissinger KV, Manning WJ: Free-breathing 3D coronary MRA: the impact of 'isotropic' image resolution. J Magn Reson Imaging 2000;11:389-393.

7 Kim WY, Danias PG, Stuber M, Flamm SD, Plein S, Nagel E, Langerak SE, Weber OM, Pedersen EM, Schmidt M, et al: Coronary magnetic resonance angiography for the detection of coronary stenoses. N Engl J Med 2001;345:1863-1869.

8 Sakuma H, Ichikawa Y, Suzawa N, Hirano T, Makino K, Koyama N, Van Cauteren M, Takeda K: Assessment of coronary arteries with total study time of less than 30 min by using whole-heart coronary MR angiography. Radiology 2005;237:316-321. 
9 Weber OM, Martin AJ, Higgins CB: Wholeheart steady-state free precession coronary artery magnetic resonance angiography. Magn Reson Med 2003;50:1223-1228.

10 Kato S, Kitagawa K, Ishida N, Ishida M, Nagata M, Ichikawa Y, Katahira K, Matsumoto Y, Seo K, Ochiai R, et al: Assessment of coronary artery disease using magnetic resonance coronary angiography: a national multicenter trial. J Am Coll Cardiol 2010;56: 983-991.

11 Yang Q, Li K, Liu X, Bi X, Liu Z, An J, Zhang A, Jerecic R, Li D: Contrast-enhanced wholeheart coronary magnetic resonance angiography at 3.0-T: a comparative study with $\mathrm{X}$ ray angiography in a single center. J Am Coll Cardiol 2009;54:69-76.
12 Pouleur AC, le Polain de Waroux J, Kefer J, Pasquet A, Vanoverschelde JL, Gerber BL: Direct comparison of whole-heart navigator gated magnetic resonance coronary angiography and 40/64 slice multi detector row computed tomography to detect coronary artery stenosis in patients scheduled for conventional coronary angiography. Circ Cardiovasc Imaging 2008; 1:114-121.

13 Schuetz GM, Zacharopoulou NM, Schlattmann P, Dewey M: Meta-analysis: noninvasive coronary angiography using computed tomography versus magnetic resonance imaging. Ann Intern Med 2010;152:167-177.
14 Einstein AJ, Henzlova MJ, Rajagopalan S: Estimating risk of cancer associated with radiation exposure from 64-slice computed tomography coronary angiography. JAMA 2007;298:317-323.

15 Chen Z, Duan Q, Xue X, Chen L, Ye W, Jin L, Sun B: Noninvasive detection of coronary artery stenoses with contrast-enhanced whole-heart coronary magnetic resonance angiography at 3.0 T. Cardiology 2010;117: 284-290.

16 Miller JM, Dewey M, Vavere AL, Rochitte CE, Niinuma H, Arbab-Zadeh A, Paul N, Hoe J, de Roos A, Yoshioka K, et al: Coronary CT angiography using 64 detector rows: methods and design of the multi-centre trial CORE-64. Eur Radiol 2009;19:816-828. 